\title{
El uso sostenible del agua en núcleos urbanos: las tarifas como herramienta de control del consumo
}

\author{
Victoria Eugenia SÁNCHEZ GARCíA \\ Universidad Carlos III \\ victoriaeugenia.sanchez@uc3m.es \\ Francisco José BLANCO JIMÉNEZ \\ Universidad Rey Juan Carlos \\ francisco.blanco@urjc.es
}

Recibido: 23 de julio del 2012

Enviado a evaluar: 26 de julio del 2012

Aceptado: 1 de octubre del 2012

\section{RESUMEN}

La Directiva Marco del Agua obliga a adoptar sistemas tarifarios que recuperen los costes del recurso agua y el establecimiento de políticas nacionales de precios que contribuyan a conseguir un uso sostenible del agua. Las tarifas del agua deben emplearse como herramienta coadyuvante de control del consumo, buscando la eficiencia y un uso sostenible del recurso. En esta investigación, hemos estudiado las características de las tarifas existentes en siete ciudades españolas, analizando el comportamiento del consumo de agua de uso doméstico en el periodo 2003-2010, para comprobar si el actual sistema tarifario español se adecua a la situación del recurso y a los objetivos de la Directiva. La conclusión principal de nuestro trabajo es que el actual sistema ha perdido su eficacia como herramienta de control del consumo, por lo que resulta necesario un replanteamiento de la política de precios y un nuevo sistema tarifario en España.

Palabras clave: gestión del agua urbana, economía ambiental, tarifas, sostenibilidad ambiental, Directiva Marco del Agua

Sustainible water use in cities: water tariff as tool for consumption control

\begin{abstract}
The Water Framework Directive requires the adoption of a tariff system that recovers the costs of water resources and the establishment of national water-pricing policies that help to achieve a sustainable water use. Water rates (tariffs) should be used as an auxiliary tool for consumption control, seeking for efficiency and a sustainable resource use. In this research, we studied the characteristics of the existing rates in seven Spanish cities, analyzing the behavior of consumption of domestic water during the period 2003-2010, in order to check whether the current Spanish rates conforms to the state of resources and the objectives of the Directive. The main conclusion of our work is that the current system has lost its effectiveness as a control consumption tool, making it necessary to rethink the pricing policy and a new tariff system in Spain.
\end{abstract}


Keywords: urban water management, environmental economy, water tariff, water rate, environmental sustainability, Water Framework Directive

L'utilisation durable de l'eau dans villes:

le tarification comme un outil de contrôle de la consommation

\begin{abstract}
RESUMÉ
La Directive-Cadre sur l'eau oblige à adopter des systèmes de tarification qui permettent de recouvrer les coûts des ressources en eau et la mise en place de politiques nationales de tarification qui permettent une utilisation durable de l'eau. Le prix de l'eau doit être utilisé comme un outil de contrôle de la consommation domestique et visant à la recherche de l'efficience et de l'utilisation durable des ressources. Dans le cadre de cette étude, nous avons examiné les caractéristiques des tarifs existants dans sept villes espagnoles en analysant le comportement de la consommation d'eau domestique durant la période 2003-2010, afin de vérifier la conformité du tarif espagnol en vigueur à l'état des ressources et los objectifs de la Directive. Ce travail nous permet de conclure que le système actuel a perdu de son efficacité en tant qu'outil de contrôle de la consommation, ce qui nous oblige à réviser la politique de prix et établir un nouveau système tarifaire.
\end{abstract}

Mots clé: gestion des eaux urbaines, économie de l'environnement, les tarifs de l'eau, développement durable, Directive-Cadre sur l'eau

\title{
1. INTRODUCCION
}

La investigación de este estudio se centra en la idoneidad de la política tarifaria del agua de uso doméstico y su eficiencia en el control del consumo de la misma, ya que si bien el agua de uso doméstico supone un porcentaje muy pequeño dentro del uso total, es tan relevante como el resto de los usos del agua y así nos lo indica la Directiva Marco del Agua (DMA 2000/60/CE) en su artículo 9 cuando dice:

"Los Estados miembros garantizarán, a más tardar en 2010 /.../ que la política de precios del agua proporcione incentivos adecuados para que los usuarios utilicen de forma eficiente los recursos hídricos /... / una contribución adecuada de los diversos usos del agua, desglosados, al menos, en industria, hogares y agricultura, a la recuperación de los costes de los servicios relacionados con el agua, basada en el análisis económico efectuado con arreglo al anexo III y teniendo en cuenta el principio de que quien contamina paga."

A fecha de publicación de este trabajo, podemos afirmar que estamos ampliamente retrasados respecto a la fecha de cumplimiento de la DMA, al menos en cuanto recuperación de costes se refiere. Además, tal y como se demostrará a través de los resultados del presente trabajo de investigación, también podemos afirmar que la política tarifaria actual no proporciona la señal adecuada al consumidor para hacer un uso eficiente y sostenible del recurso del agua en España. 


\section{SOBRE EL ESTADO DEL RECURSO Y SU USO}

Consideramos oportuno introducir y aclarar la situación del agua como elemento integrante de un servicio público. El abastecimiento de agua es uno de los servicios básicos para el desarrollo demográfico, social y económico de una sociedad. En España, su prestación tiene carácter obligatorio por parte de las Administraciones Públicas. Conforme a lo dispuesto en la Ley 7/1985, de 2 de abril, Reguladora de las Bases de Régimen Local, el abastecimiento de agua a los hogares es un servicio de competencia municipal, aunque este servicio puede ser gestionado directamente por los ayuntamientos o por terceros (art. 25.2 y 26.1), es decir, puede ser gestionada por entidades públicas, privadas o mixtas.

Al hablar del agua, una de las primeras afirmaciones que suele escucharse es que el consumo de agua urbana tiene poco peso en relación a otros usos, particularmente frente al agrícola. Ciertamente el porcentaje de agua usada para cubrir las necesidades de las urbes y de sus habitantes, suele ser inferior al uso que de ella hacen los sectores productivos en España. Ahora bien, no podemos olvidar dos cuestiones: en primer lugar, que su suministro, el abastecimiento de agua potable a las viviendas, es prioritario sobre el resto de usos; y, en segundo lugar, porque en algunas regiones su peso respecto del uso global de agua sí es considerable. Así, una política de aguas, para que sea correcta, debe tener presente todos y cada uno de los factores que inciden sobre los recursos hídricos, incluido el uso urbano y, dentro de este, el doméstico.

En este sentido, no podemos obviar que "el abastecimiento a los hogares consiste en algo más que poner a su disposición una cantidad de agua a cambio de un precio" (MMA, 2007:185). Ciertamente, el abastecimiento doméstico constituye el único uso del agua como bien esencial de consumo por parte de las personas. Como tal bien esencial debe garantizarse la disponibilidad del recurso en cantidad y calidad (potable), con independencia de los condicionantes climáticos. Esta necesidad, conlleva disponer de recursos en una cantidad superior a la de otros usos (agua capturada) y una calidad sensiblemente superior (potable).

Se puede hacer un uso consuntivo del agua o un uso no consuntivo del recurso. El uso doméstico es un uso consuntivo, como lo es el industrial o el agrícola. Entre los usos no consuntivos se encuentran el uso ambiental (las necesidades para el funcionamiento ecológico del medio), pero también otros usos humanos no consuntivos, como son los recreativos en el medio natural (desde la natación o la pesca, a la observación del paisaje) o el uso no consuntivo pero productivo del agua cuando es usada como vía de transporte. Según datos publicados por la Agencia Europea de Medio Ambiente (AEMA) en 2010, el consumo de agua entre los distintos sectores económicos varía considerablemente de un país a otro, de una región a otra, dependiendo de las condiciones naturales y de las estructuras económicas y demográficas. Varían de forma relevante los usos del recurso que se hacen en buena parte de Europa, respecto de los usos españoles (país del Sur) lo que genera equívocos entre aquellos que tienden a extrapolar los datos sobre el recurso agua y sus usos que nosotros conocemos al resto de países europeos. 
En Europa, la media establecida indica que el $45 \%$ de las aguas capturadas se emplean para refrigeración durante la producción de energía, un $22 \%$ en agricultura, un $21 \%$ para abastecimiento público y un $12 \%$ en industria. Estas medias enmascaran un uso bastante dispar del agua según áreas geográficas y países, resultando esclarecedoras a la hora de intentar comprender por qué se producen ciertas presiones legislativas. Así, al desglosar los datos se observa que en Francia y Alemania la mayoría del agua extraída se utiliza para producir electricidad (64\%), en tanto que en Grecia y España, el agua se utiliza principalmente para agricultura ( $88 \%$ y $81 \%$ respectivamente). La Figura 1 muestra claramente como sólo en el consumo doméstico hay una tendencia creciente de captación (y consumo) en los países del sur de Europa, y los elevados consumos de la región oeste que están en fase de corrección, como el resto de las captaciones cualquiera que sea su uso previsto. Del mismo modo que destaca el alto consumo agrícola del agua de los países del Sur de Europa, en la misma área donde los consumos urbanos no decrecen.

Figura 1. Tendencias en las captaciones de agua para los distintos Usos en Europa por áreas geográficas (1990-2007, en millones de $\mathrm{m}^{3} /$ año)

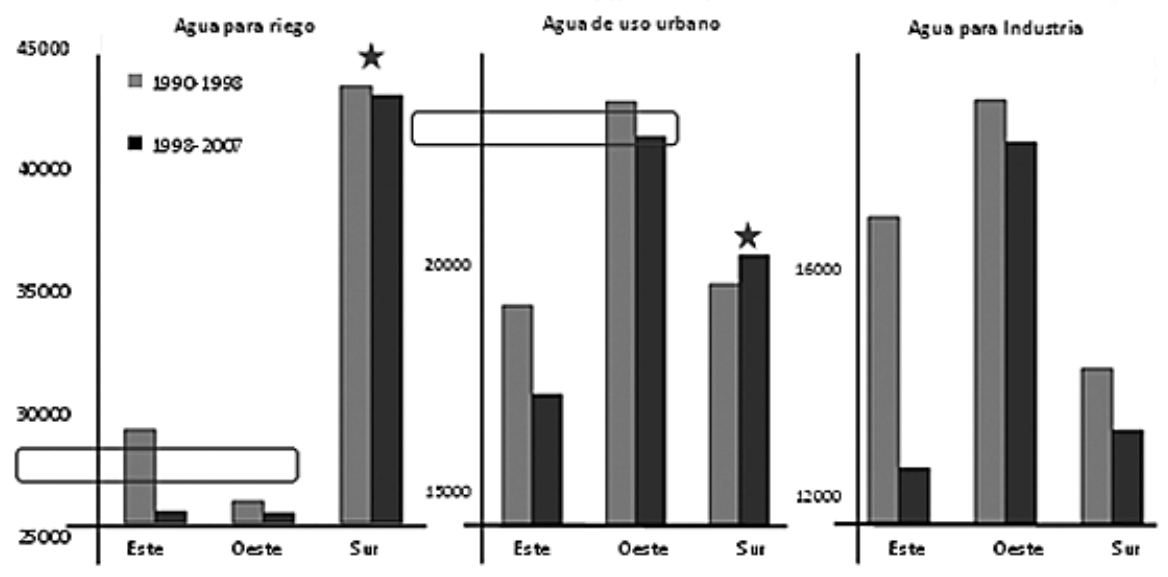

Fuente: EEA, 2010 (el resaltado es nuestro)

Los porcentajes de captación y uso de agua en Europa, la media, no son comparables con los usos registrados en España y esta disparidad se acrecienta al respecto de los países de Centroeuropa o el Este. Según los datos del INE, en España en torno al $81 \%$ del agua es usada en agricultura, frente al $22 \%$ de la media europea; en tanto que las aguas para abastecimiento urbano suponen un $12,4 \%$ frente al $21 \%$ de la media europea ${ }^{1}$.

${ }^{1}$ Los datos del INE de agua usada no incluyen las de uso energético. 
No obstante, en nuestro contexto europeo, al desglosar las cifras observamos que el uso principal del agua es urbano y no para riego. En este punto, el de las tendencias de uso del agua, conviene resaltar que aproximadamente el $75 \%$ de la población europea vive en áreas urbanas y se estima que en el 2020 el porcentaje aumentará hasta el $80 \%$, aunque en algunos países el porcentaje puede ser mayor (EEA, 2006:5). Ahora bien, es importante ver cómo será el desarrollo de las ciudades, porque los requerimientos de agua no son los mismos en ciudades de desarrollo vertical que en aquellas donde el área metropolitana es extensa y abundan, en torno al centro de la ciudad, los desarrollos urbanísticos de tipo residencial, con baja densidad de población y abundantes zonas ajardinadas. Históricamente, el crecimiento en extensión de las ciudades ha sido impulsado por aumento de la población urbana. Sin embargo, como veremos al realizar el análisis de resultados, hoy en día tan importante o más que la presión demográfica, es el deseo de muchas personas de tener nuevos estilos de vida en ambientes suburbanos, fuera del centro de la ciudad en viviendas unifamiliares con zonas verdes que emplean agua doméstica potable "de puertas hacia fuera" de la vivienda.

La Figura 2 muestra los volúmenes de agua captada y utilizada por los distintos sectores en el periodo de estudio 2001-2006, siendo éste el último año para el cual el INE tiene publicada información sobre aguas, si bien en el estudio de casos utilizamos información actualizada a 2010, por haberla obtenido de las suministradoras. Durante la recopilación de datos para este estudio, hemos constatado la existencia de un "baile" de cifras en materia de agua según sea la fuente el INE o el Ministerio, variación que se hace más patente al analizar con detalle la información, si bien al abordarse tendencias puede considerarse no significativa.

Centrándonos en los usos urbanos, como siempre suele suceder con las cifras globales, existen importantes diferencias de consumo per cápita entre las diferentes Comunidades Autónomas. Atendiendo a los datos publicados por el MMA en 2007 el rango de valores del agua facturada va desde los 124 litros habitante/día de la cuenca Balear, hasta los 184 en la Internas de Cataluña, siendo la media española de 165 litros/habitante/día en 2001. Ahora bien, según los datos facilitados al Ministerio por los Organismos de cuenca para ese mismo año, el rango de valores varía desde los 116 litros/habitante/día de Canarias y los 189 litros/habitante/día de la Cuenca de Galicia Costa, y no el valor de las Cuencas Internas de Cataluña, con 168 litros/habitante/día como ofrece el INE. Como hemos señalado, no es que las variaciones sean significativas, pero sí lo es el hecho de la falta de homogeneidad de los datos y, sobre todo, retraso en su publicación.

En base al comportamiento respecto del consumo, podemos agrupar las Comunidades en tres bloques, las que se encuentran sistemáticamente en valores superiores a la media, las que se encuentran en entorno a la media, y las que registran los mejores comportamientos. Los datos estudiados por el MMA para el periodo 1996-2003, hacían referencia al comportamiento "sistemático" de algunas Comunidades distribuyéndolas del siguiente modo: 
a) Por encima de la media: Cantabria, Castilla La Mancha, Andalucía, Cataluña, Aragón y Castilla León.

b) En niveles similares al promedio nacional: C. Madrid, Extremadura, C. Valenciana y Asturias.

Figura 2.- Volumen de captaciones y usos del agua en España (2001-2006)
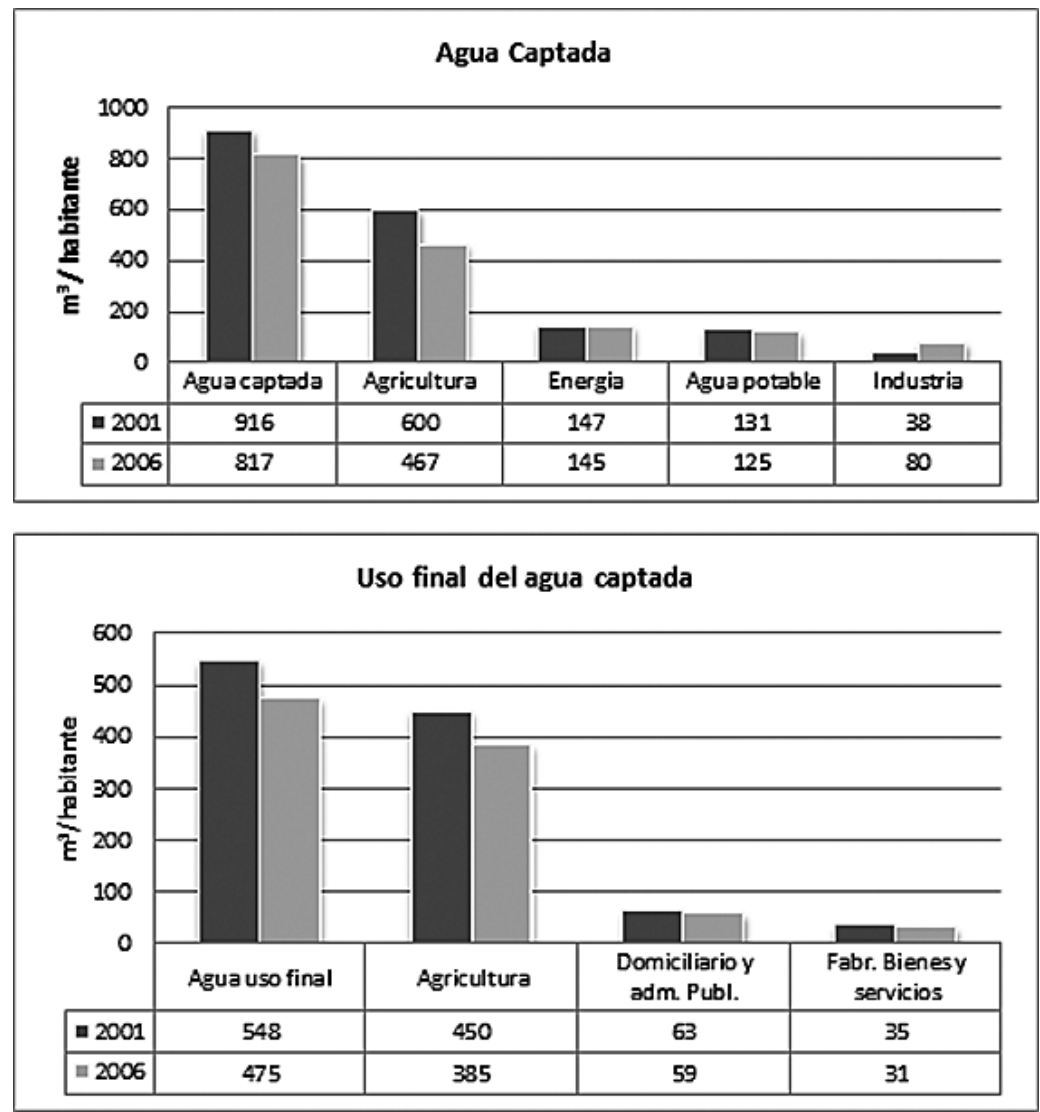

Fuente: Elaboración propia con datos del INE

c) Por debajo de la media: I. Baleares, I. Canarias, La Rioja, Galicia, País Vasco y Murcia.

Como paso previo a la realización de nuestro estudio, procedimos a analizar los consumos (litros/habitante/día) en las distintas Comunidades Autónomas para el periodo 2003-2010, observando una tendencia decreciente en el agua de consumo doméstico, siendo la media de 149 litros/habitante/día en 2010. Mediante el estudio de casos, comprobamos si esta tendencia decreciente en el consumo es debida a la eficacia del sistema de tarifas (precio) como herramienta de control, o si tiene su origen en otros factores, puesto que las grandes cifras nos muestran que el comporta- 
miento en todas las Comunidades Autónomas no es homogéneo y mucho menos lo son las tarifas y los precios. Así, al estudiar el comportamiento de las Comunidades Autónomas respecto del uso del agua en el periodo 2003-2010, se observan cambios.

Utilizando la terminología del Ministerio, podríamos decir que hay un grupo de Comunidades "sistemáticamente malas", en el sentido de que no se observan esfuerzos de reducción del consumo o que estos no han sido efectivos; haciéndose en general una gestión del recurso en base a un modelo de oferta, modelo que hace años ha sido sustituido en buena parte de la Unión Europea por un modelo de uso sostenible del agua (Sánchez, 2012:65). Las Comunidades con valores más altos de consumo, por encima de la media, son Cantabria, Asturias o Extremadura. En el extremo opuesto, con un comportamiento regular o "sistemáticamente bueno", por debajo de la media, se encuentran Ceuta y Melilla, Baleares o Navarra. Ahora bien, nos parece más interesante llamar la atención sobre dos tendencias muy marcadas en ese periodo de tiempo: en el lado positivo, los consumos decrecientes de Cataluña; en el lado negativo del comportamiento el marcado empeoramiento de la C. Valenciana, así como la tendencia de Murcia.

Conviene señalar que este mal comportamiento en cuanto a consumos, además de la presión que ejerce sobre la oferta del recurso (mayor captación para garantizar el abastecimiento y una mayor presión política para obtener recurso extra vía trasvase), tiene otro impacto negativo, la emisión de mayores cantidades de efluentes que exigen un esfuerzo en depuración, pudiendo incidir en mayor o menor medida en la calidad de las aguas a las que son vertidas. Así pues, la incidencia sobre el Ciclo Integral del agua es doble.

\section{OBJETO DEL ESTUDIO}

Partimos de la hipótesis de si el sistema tarifario actual se adecua, o no, a la realidad hidrológica española y a las necesidades actuales del sector de manera sostenible, conforme a los requerimientos de la DMA. Sabemos que los requisitos que debería cumplir este sistema para considerarlo adecuado son: a) que sea eficiente desde la perspectiva económica (que cumpla el principio de recuperación de costes tal y como indica la DMA); b) que lance una señal al usuario, con independencia del tipo de usuario, respecto a la escasez del recurso, para que haga un uso eficiente del recurso agua, optimizando el consumo; c) que sea sostenible, siendo necesario para ello evaluar el equilibrio entre los costes financieros, ambientales y del propio recurso.

Para el desarrollo de este trabajo establecimos una serie de metas:

- Investigar las metodologías, para el estudio de los indicadores y fuerzas motrices a analizar comprobando la eficacia del sistema de tarifas.

- Ver la influencia del precio-tarifa del agua en las fuerzas motrices del consumo.

- Compilar el perfil tarifario de diferentes ciudades piloto, así como de los "drivers" (fuerzas motrices) seleccionados.

- Estudio y análisis de los resultados de manera individual e integrada.

- Obtención de conclusiones para proponer ajustes del modelo tarifario existente. 
Conforme a los recursos disponibles, seleccionamos siete ciudades, cada una de ellas perteneciente a una Demarcación Hidrográfica distinta, para contrastar los resultados con una situación de calidad/cantidad de recurso hídrico disponible también diferenciada (Tabla 1). Estas ciudades son: Barcelona, Bilbao, Ciudad Real, A Coruña, Madrid, Salamanca y Sevilla.

Tabla 1. Cuencas y Demarcaciones Hidrográficas de las ciudades analizadas

\begin{tabular}{|l|l|l|}
\hline \multicolumn{1}{|c|}{ Mumicipio } & \multicolumn{1}{|c|}{ Cuenca Hidrogáfica } & \multicolumn{1}{c|}{ Demarcacion Hidrogáfica } \\
\hline Barcelona & CC.Internas de Cataluña & D.H. de Cataluña \\
\hline Bilbao & CC.Internas del Pais Vasco & D.H. del Pais Vasco \\
\hline Ciudad Real & C. del Tajo & D.H. del Tajo \\
\hline Conuña, A & C. Interna Galicia-Costa & D.H. Galicia Costa \\
\hline Madrid & C. del Tajo & D.H. del Tajo \\
\hline Salamanca & C. del Duero & D.H. Duero \\
\hline Sevilla & C. del Guadalquivir & D.H. del Guadalquivir \\
\hline
\end{tabular}

Fuente: Elaboración Propia

Los operadores correspondientes a los municipios objeto de este estudio se detallan en la Tabla 2, destacando que tres de ellos tienen operadores de agua privados, dos de ellos operadores públicos y los restantes empresas mixtas.

Tabla 2. Operadores de Agua en las ciudades analizadas

\begin{tabular}{|l|l|l|}
\hline Muricipio & \multicolumn{1}{|c|}{ Operador de Agua } & \multicolumn{1}{c|}{ Tipo de Operador } \\
\hline Barcelona & Agbar. Aguas de Barcelona & Privado \\
\hline Bilbao & Consorcio de Aguas Bilbao-Bizkaia & Pública \\
\hline Ciudad Real & Aguagest o Hidroguadiana & Privado \\
\hline Conuña, A & Emalcsa & Esa. Privada Municipal \\
\hline Madrid & Canal de Isabel II & Pública \\
\hline Salamanca & Aqualia & Privado \\
\hline Sevilla & Emasesa & Esa. Privada Municipal \\
\hline
\end{tabular}

Fuente: Elaboración Propia

\section{METODOLOGIA}

Para este trabajo se ha obtenido información de distintos organismos e instituciones, caso de Comunidades Autónomas, Ayuntamientos correspondientes a las ciudades analizadas, Instituto Nacional de Estadística (INE), Asociación Española de Abastecimientos de Agua y Saneamiento (AEAS), Ministerio de Medio Ambiente (MMA), Confederaciones Hidrográficas y las distintas empresas suministradoras de agua. Así como de los distintos institutos de estadística de las Comunidades donde se ubican las ciudades piloto, entre otros del Instituto de Estadística de Cataluña (IDESCAT), Instituto Gallego de Estadística (IGE), Instituto de Estadística de la Comunidad de Madrid e Instituto Vasco de Estadística (EUSTAT) y, por último, la Dirección General del Catastro. 


\subsection{ANÁLISIS FPEIR-DPSIR}

Como paso previo a la selección de variables a considerar en el estudio, se procedió a realizar un análisis de causalidad aplicado al agua de consumo doméstico, usando la metodología de análisis Fuerzas Motrices-Presiones-Estado-ImpactoRespuesta (FPEIR) - más conocida por sus siglas en inglés Drivers-Pressures-StateImpact-Response (DPSIR) - que es una variante desarrollada por la Agencia Europea del Medio Ambiente de un modelo más sencillo creado por la OCDE para analizar situaciones relativas a problemas ambientales. "Las actividades humanas ejercen presiones sobre el medio y cambian su calidad y la cantidad de los recursos naturales (estado de las condiciones ambientales). La sociedad responde a esos cambios mediante políticas ambientales, sectoriales o económicas (respuestas sociales)" (OECD, 1993:5). En este proceso, se genera una interacción permanente entre la presión ejercida sobre el medio, o recurso de ese medio, y la respuesta obtenida. Partiendo de este modelo, la Agencia Europea de Medioambiente elaboró, para hacer el segundo informe sobre la situación del medio ambiente en Europa (informe Dobris, 1998), un nuevo marco analítico para poder analizar las interrelaciones existentes en un proceso causa-efecto. Este modelo nos parece más adecuado a nuestros fines puesto que incorpora las causas de presión (las llamadas fuerzas motrices, agentes y medios, que inevitablemente provocan alteraciones en el medio); y también los impactos, es decir, las consecuencias de las modificaciones del estado del medio en un momento de tiempo dado (Figura 3).

Para cada punto del análisis se fijaron variables que pueden/deben ser objeto de estudio, asignando indicadores para el seguimiento. El punto central del análisis constituye el estado de aquello que va a ser objeto de análisis (cantidad y calidad), para luego pasar a estudiar cuáles han sido las presiones que han dado lugar a cambios positivos y/o negativos. A continuación se vincularon estos procesos y presiones a las fuerzas motrices de la actividad humana, para finalmente pasar a comprobar las respuestas que se están dando - o pueden darse- desde distintas instancias político-administrativas, empresariales y sociales a fin de evitar, compensar o paliar los cambios.

Aplicamos el modelo analítico descrito, FPEIR/DPSIR al agua (Figura 4), si bien previamente analizamos cuál era el estado del recurso natural agua y las presiones sobre el recurso en España y resto de la Unión Europea. Entre las fuerzas motrices identificadas se encuentra el consumo de agua en los hogares, dentro del apartado "agua de uso/consumo urbano".

Figura 3.- Modelo de análisis DPSR desarrollado por la AEMA (1998)

Figura 3.- Modelo de análisis DPSR desarrollado por la AEMA (1998).

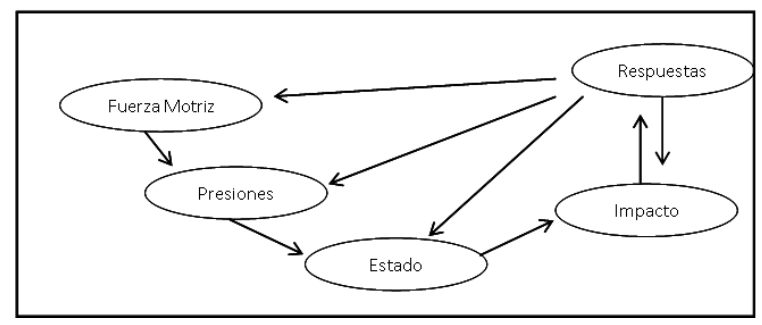


Centrándonos más concretamente en el consumo doméstico, en la literatura encontramos una serie de variables que, teóricamente, guardan relación con el nivel de consumo, direccionando la actividad humana e influyendo en los usos del agua, en forma y cantidad. Así, el uso doméstico, que varía dependiendo de una serie de variables como son: población (población residente y flotante), estructura del hogar (habitantes por vivienda), capacidad adquisitiva (renta per cápita, renta bruta familiar disponible), cantidad de viviendas habitadas y su distribución espacial, tipología de la vivienda, climatología, tecnologías aplicables y las costumbres de uso del agua individuales y hábitos sociales. Algunas de estas variables han sido consideradas en trabajos realizados en zonas con escasez de agua, caso de Australia y de California en Estados Unidos, a fin de adoptar políticas de agua acordes al estado del recurso. En estos lugares, tras realizar estudios de situación y tendencias, se han cambiado las políticas de gestión (y tarificación) que han dado lugar a importantes disminuciones en el consumo de agua urbana y, particularmente del consumo doméstico. Así, en el periodo del 2000-2009, en California se redujeron los consumos per cápita en un $20 \%$, en tanto que en Australia, se obtuvieron descensos del 30\% (Lund y Cahill, 2011). Los resultados obtenidos en Australia mediante la aplicación de medidas de optimización del uso del agua utilizando una combinación de fomento del uso de tecnologías y precios, sobre todo en el uso de agua doméstica "de puertas hacia fuera", son indiscutibles (WSAA, 2010).

En el análisis cuantitativo de los casos estudiados, se prescindió de las variables del FPEIR/DPSIR que tienen un marcado carácter sociológico (como son las costumbres de uso), manteniéndose en el estudio de casos el resto de variables a fin de poder hacer el análisis de la eficacia de una de las posibles herramientas o elementos de respuesta para el control de uso: el sistema de tarifas (precios).

\subsection{CALCULO DE TARIFAS MEDIAS}

La metodología utilizada para el cálculo de tarifas es la utilizada por la AEAS y aceptada por el MMA. Para el cálculo de los precios medios del agua, fue necesario recopilar las 56 ordenanzas fiscales de aplicación en las 7 ciudades seleccionadas, para los años 2003-2010, periodo objeto del estudio, creando con esta información una base de datos conteniendo los distintos bloques de tarifa según el consumo. A fin de facilitar la explotación de datos, se elaboró una matriz de doble entrada con la que recoger los datos relativos a la estructura tarifaria aprobada en la ordenanza fiscal de cada año para cada una de las ciudades.

La estructura de la base de datos se diseñó tomando la estructura cuantitativa de las tarifas como eje central. Para el cálculo del pago por los servicios del agua para las siete ciudades del estudio se tuvo en cuenta el consumo que publica el INE anualmente, dado en litros/habitante/día. Para obtener el consumo por vivienda se multiplica el dato anterior por el número de personas por vivienda publicado por el INE -dato que se publica a nivel de provincia-. Con el consumo obtenido $\left(\mathrm{m}^{3} /\right.$ vivien$\mathrm{da} / \mathrm{mes}$ ) se aplicó el sistema tarifario vigente (de nuestra base de datos) sumando, por un lado la tarifa fija (siempre) y, por otro, la tarifa variable según el tramo de consumo en el que se sitúe la vivienda, procediendo a aplicar el importe en euros corres- 
pondiente a cada tramo multiplicado por el número de $\mathrm{m}^{3}$ que están incluidos en dicho tramo de consumo.

Para cada una de las ciudades los resultados se desglosan en abastecimiento y saneamiento (alcantarillado y depuración) diferenciando entre una parte fija mensual y una parte variable en función de los $\mathrm{m}^{3}$ consumidos. La parte fija corresponde al pago por abastecimiento y saneamiento del agua (euros/mes) y comprende los siguientes apartados: cuota de servicio, cuota de servicio con consumo mínimo, cuota de mantenimiento y conservación del contador, canon y otros recargos adicionales. La parte variable del pago por abastecimiento y saneamiento de agua (euros $/ \mathrm{mes}$ ) comprende: cuota de consumo (municipal) y canon (provincial o autonómico).

\subsection{ANALISIS ESTADÍSTICO: SIMPLE Y AVANZADO}

Con el estudio de casos pretendemos a través de un análisis inicial de los datos que corresponden a las variables seleccionadas, comprobar su comportamiento longitudinal (a través del tiempo), a través de una análisis univariante y posteriormente realizar un análisis bivariante estudiando su correlación ${ }^{2}$, utilizando para ello metodología de análisis estadístico a través del programa Statistical Product And Service Solutions (SPSS) y también una base de datos para facilitar su posterior explotación y análisis en hoja de cálculo, así como su representación gráfica. El objetivo de nuestro análisis de correlación es obtener la interacción de las variables analizadas (variables independientes) entre sí, centrándonos fundamentalmente en el análisis de estas variables con respecto al consumo (variable dependiente).

Una vez finalizado el análisis de correlaciones, y comprobado cuales son significativas, pasamos a expresar esa relación de manera matemática planteando una ecuación que conecte las variables, utilizando para ello el análisis de regresión lineal. Esta técnica estadística es la utilizada para estudiar la relación entre variables.

El propósito en el análisis de regresión simple es doble: averiguar en qué medida la variable dependiente puede estar explicada por las variables independientes; y obtener predicciones en la variable dependiente a partir de las variables independientes. Si bien en nuestro estudio solo nos centramos en el primer propósito, dejando las predicciones para futuras investigaciones, dado que para ello necesitaríamos realizar proyecciones a futuro de las variables independientes.

Los resultados nos llevan a una serie de ecuaciones, que nos explican el consumo a partir de las variables seleccionas. Para cada una de las variables independientes, podemos integrar los resultados de las ciudades donde se ha dado esta relación, si bien en este caso de estudio consideramos que no sería necesario integrar los resul-

2 El concepto de correlación se refiere al grado de variación conjunta existente entre dos o más variables. Nosotros nos centraremos en el estudio de un tipo particular de correlación llamada lineal y nos vamos a limitar a considerar únicamente dos variables (simple). El coeficiente de correlación nos sirve para cuantificar el grado de relación lineal existente entre dos variables cuantitativas. 
tados en una sola ecuación pues cada ciudad, comunidad autónoma, demarcación hidrográfica tienes su propia idiosincrasia y por tanto debería tener su propia ecuación. Está en general sería:

$$
Y_{i}=B_{0}+B_{1} \cdot X_{i}
$$

siendo:

$\mathrm{Y}_{\mathrm{i}}$ la variable dependiente o criterio (consumo).

$\mathrm{X}_{\mathrm{i}}$ la variable independiente o predictoria (población, población ocupada, renta bruta familiar disponible, precio del agua).

$\mathrm{B}_{0}$ es el origen de la recta de regresión.

$\mathrm{B}_{1}$ es la pendiente de la recta de regresión.

De esta forma podemos pronosticar el consumo a partir de unos indicadores que definiremos como idóneos y nos irán indicando si la política tarifaria elegida está cumpliendo con los objetivos establecidos, en cuanto a control de consumo se refiere. De igual modo, si realizamos un análisis de regresión simple en la que establecemos la variable independiente como el "precio del agua", en lugar del consumo, podemos comprobar si una vez establecidos los indicadores idóneos con los que está correlacionado el precio y establezcamos una proyección a futuro de éstos, podamos verificar si ese precio proyectado a través de la ecuación de regresión permitirá cubrir los costes financieros y ambientales que nos pide la DMA, una vez estos costes hayan sido claramente definidos y cuantificados.

Con el fin de profundizar en algunas relaciones entre estas variables, hemos realizado el que hemos denominado Análisis avanzado. Dentro del mismo procedemos a realizar los siguientes análisis de consumo y precio por tamaño de población; comparativo por ciudad de cada variable; de elasticidades precio de la demanda/consumo: análisis del consumo versus renta disponible y análisis del consumo del agua respecto de la temperatura.

Una vez recopilados los datos en el sistema procedemos a analizar los resultados, viendo la evolución a través del periodo de análisis (2003 a 2010) así como la interrelación existente entre las variables. Comenzamos con un análisis de todas las combinaciones posibles de dos variables de todas las analizadas en este estudio (población, población ocupada, renta bruta familiar disponible, número de viviendas, consumo de agua y precio del agua). Para a continuación, hacer una valoración de la relación existente entre las dos variables que estemos analizando, realizamos un análisis de correlación lineal para determinar el grado de asociación entre esas dos variables. En particular, hemos utilizado el coeficiente de Pearson (r) cuya fórmula se expone seguidamente:

$$
\mathrm{r}=\frac{\mathrm{Sxy}}{\mathrm{Sx} \mathrm{Sy}}
$$


siendo:

$\mathrm{r}=$ coeficiente de correlación de Pearson

$S_{x y}=$ covarianza entre las variables " $x$ " e " $y$ "

$\mathrm{S}_{\mathrm{X}}=$ desviación típica de " $\mathrm{x}$ "

$\mathrm{S}_{\mathrm{y}}=$ desviación típica de " $\mathrm{y}$ "

Este coeficiente de correlación de Pearson solo puede tener valores comprendidos entre -1 y 1 . Ahora bien:

Si $r=1$ existe correlación perfecta positiva y la relación funcional entre ambas variables es exacta y positiva, variando ambas variables en el mismo sentido (al aumentar una aumenta la otra y al disminuir una disminuye la otra).

Si $\mathbf{r}=\mathbf{- 1}$ existe correlación perfecta negativa y la relación funcional entre ambas variables es exacta y negativa, variando ambas variables en el sentido opuesto (al aumentar una disminuye la otra y al disminuir una aumenta la otra).

Si $\mathbf{r}=\mathbf{0}$ la correlación es nula y las variables no están asociadas, siendo imposible encontrar una relación funcional entre ellas.

Si $\mathbf{0}<\mathbf{r}<\mathbf{1}$ la correlación es positiva, pero el grado de asociación entre las dos variables será mayor a medida que $\mathrm{r}$ se acerca más a 1 , y será menor a medida que $r$ se acerca más a cero.

Si $\mathbf{- 1}<\mathbf{r}<\mathbf{0}$ la correlación es negativa, pero el grado de asociación entre las dos variables será mayor a medida que $\mathrm{r}$ se acerca más a -1 , y será menor a medida que $r$ se acerca más a 0 .

\section{RESULTADOS}

La Tabla 3 muestra los resultados de los cálculos obtenidos diferenciando la parte del precio que corresponde al servicio de abastecimiento y la parte correspondiente a saneamiento, así como la diferenciación entre la parte fija de la parte variable de la tarifa en cada tipo de servicio. Tal y como señala el Ministerio de Medio Ambiente en su Informe de 2007 sobre el Agua y la Economía Española: "el análisis detallado de cómo los precios afectan a la demanda de agua en los hogares españoles es una tarea pendiente" (MMA, 2007c:32). Hay una opinión generalizada de que el precio influye poco cuando el agua es muy barata, aunque se le reconoce un efecto mayor a medida en que aumenta el precio. Así, en Australia los precios y la tecnología están siendo utilizados para optimizar los usos domésticos, tanto en usos esenciales como no esenciales. Según los estudios realizados por la Water Services Association of Australia, WSAA 2010, el consumo doméstico de agua que se realiza en el exterior de las viviendas ("de puertas hacia fuera"), es mucho más sensible a las variaciones de precio, mucho más elástico, que el interior.

Los procesos demográficos ejercen presión sobre la cantidad y calidad del recurso disponible. Estos generan presión sobre el estado del recurso a través de la demanda de agua, su consumo y su contaminación como consecuencia de su uso. No sólo se trata del crecimiento en el número de habitantes (que en España es escaso, según los datos del INE), también tiene incidencia la estructura de edad de la población por influencia en los patrones de consumo de agua, así como las migraciones del medio rural al medio urbano (Bullock et al., 2009; Björklund et al., 2009). Dentro de la variable población, 
nosotros hemos seleccionado la población general, y la población ocupada. Los resultados nos indican que la población si incide en el consumo pero no en todas las ciudades. No existe correlación entre el consumo y la población en Bilbao, ni en Madrid, ni en Sevilla. Concluimos que no es una variable adecuada. En el caso de Bilbao, siendo el País Vasco una de las zonas con más densidad poblacional resulta contradictorio el resultado. En el caso de Madrid, puede deberse a que no toda la población está empadronada y que también existe una población flotante que viene a la ciudad por trabajo, negocios, turismo, etc., que no está contabilizada como población en el censo, pero que si incide en el consumo. Habría que tener en cuenta otro tipo de población que no está aquí reflejada, por ejemplo, la población flotante, la población no empadronada, la densidad de población, etc. En cuanto a la población ocupada, sólo nos da correlación con el consumo en la ciudad de Madrid. El consumo de agua puede disminuir en el lugar de trabajo, porque los individuos tendamos a beber agua embotellada en este emplazamiento, porque vamos menos frecuentemente al aseo, etc. Esta variable la descartaríamos.

La población se encuentra muy desigualmente distribuida a lo largo del territorio español. Una de cada cuatro personas habita en grandes núcleos metropolitanos de Madrid y Barcelona, lo que tiene su reflejo en la presión que ejerce la demanda sobre la cuenca del Tajo y las cuencas internas de Cataluña. No obstante, las cuencas españolas más densamente pobladas son las que abastecen al País Vasco (600 habitantes $/ \mathrm{m}^{3}$ ) y la de Cataluña (340 habitantes $/ \mathrm{m}^{3}$ ).

La estructura de la población también tiene incidencia sobre el consumo. En España, al igual que en países de nuestro entorno, está aumentando el número de personas que viven solas. Las personas que viven solas tienden a consumir más por ineficiencia, ya que en las viviendas se observan economías de escala en el consumo de agua (Höglund, 1999). Al pasar de una vivienda en la que vive una persona sola a una vivienda con 2 habitantes, se produce una disminución del $41 \%$ del consumo (Cubillo, 2008:115). Además, las personas jóvenes consumen más que personas de mayor edad, quienes tienden a adoptar medidas de ahorro frente a actitudes menos "cuidadosas" de jóvenes (March y Saudí, 2009:302).

La cantidad de agua demandada por núcleo familiar depende de varios factores como, por ejemplo, su capacidad de compra (renta), el precio del agua, el tamaño y tipo de vivienda. Las familias con niños pequeños o con adolescentes muestran mayores consumos, pudiendo observarse un incremento de hasta un $199 \%$ en el consumo (Cubillo, 2008:105). El tamaño medio de las unidades familiares se encuentra en disminución, habiendo disminuido de 3,4 en la década de los 80 , hasta un 2,9 en la primera década del siglo XXI (INE, 2005).

\footnotetext{
3 Aunque inicialmente se consideró incluir alguno de estos indicadores en el estudio, el problema que nos encontramos es que el dato de $n^{0}$ de personas por vivienda solo existe en el INE hasta el 2005, y el resto de los datos se encuentra a nivel provincial pero no municipal y además sólo se realiza como encuesta puntual sin una continuidad temporal.
} 
Respecto a las viviendas, en el estudio hemos considerado el número de viviendas residenciales, donde observamos existe correlación en todas las ciudades a excepción de A Coruña y Bilbao. Como indicadores de vivienda ${ }^{3}$ consideramos fundamental incluir otras variables como son: el número de personas/vivienda, el tipo de vivienda (unifamiliar, residencial...) y $\mathrm{n}^{\mathrm{o}}$ de baños por vivienda, entre otras.

En el caso español, la variable vivienda, tiene la singularidad de estar sobredimensionada respecto de la evolución demográfica, lo que puede causar distorsión al correlacionarla con otras variables. Esta "burbuja inmobiliaria" se observa claramente en el periodo 1991-2001, durante el cual el número de viviendas principales superó en casi cuatro veces la tasa de crecimiento demográfico, dándose crecimientos muy superiores al promedio en las islas y en las cuencas del Segura y mediterráneas andaluzas (MMA, 2007c:29).

Según Parés et al., 2004, el consumo exterior de agua (para riego jardín y/o piscina) muestra grandes variaciones dependiendo de la tipología edificatoria, pudiendo superar éste los 90 litros/persona/día en viviendas de elevado poder adquisitivo. En un estudio realizado por Domene y Saurí, en el área metropolitana de Barcelona, 2003, se muestra como el consumo de agua en viviendas unifamiliares se viene a situar entre los 300 litros/persona/día y los 400 litros/persona/día, variando en función de la renta, según las dimensiones que tienen los jardines (dimensiones $>200$ $\mathrm{m} 2$, puesto que alrededor de un $30 \%$ del consumo total de agua en este tipo de vivienda está destinado al riego del jardín).

Esta misma idea queda corroborada por otros estudios. En el trabajo de Cubillo, 2008, en viviendas en altura (edificios), los consumos del año 2006 se estimaron en 118 litros/habitante, en tanto que para viviendas unifamiliares la cifra fue de 241 litros/habitante. La variable que más discrimina el consumo de agua doméstico en la Comunidad de Madrid es la presencia de "jardín propio o parcela" (Cubillo et al., 2008:162). En estudios realizados en Estados Unidos, se vio que el consumo exterior de agua en la vivienda podía llegar a ser entre un 57,5\% hasta un $72,3 \%$ superior (Mayer, et al., 1999:97), en el caso referido, este incremento se eleva hasta el 104\%. Así pues, el gasto hídrico destinado a jardinería privada, si se continúa desarrollando el modelo basado en urbanización de baja densidad, podría desestabilizar la situación de los recursos hídricos en algunas zonas, por lo que se hace necesaria la adopción de medidas que puedan disminuir el consumo de agua en este ámbito. Algunas de estas medidas podrían ser la continuidad con el modelo de ciudad mediterránea, tradicionalmente compacta y menos consumidora de recursos sostenible (Muñoz, 2003).

También Rico Amorós advierte en sus trabajos de que "en los modelos de urbanización difusa con predominio de viviendas unifamiliares con jardín y piscinas de uso estacional, se elevan los consumos y se reduce el rendimiento técnico en comparación con los consumos urbanos de alta densidad con viviendas construidas en bloque" (2007:10).

La renta incide en el tipo de vivienda que se adquiere o alquila, tanto para residencia continuada como para uso estacional, y también en los equipamientos con los que se dota la vivienda; los cuales, a su vez, inciden en los consumos (Figura 5). Para 
Tabla 3.- Pagos de agua por vivienda ( $€ /$ mes).

\begin{tabular}{|c|c|c|c|c|c|c|c|c|c|c|c|}
\hline \multicolumn{3}{|c|}{ Barcelon a } & \multicolumn{3}{|c|}{$\begin{array}{l}\text { ABASTECIMIENTO ( } € / m e s \text { y } \\
\text { vivienda) }\end{array}$} & \multicolumn{3}{|c|}{$\begin{array}{c}\text { SANEAMIENTO (E/mes Y } \\
\text { vivienda) }\end{array}$} & \multicolumn{3}{|c|}{$\begin{array}{c}\text { TOTALPAGO ( } € / \text { mesy } \\
\text { vivienda) }\end{array}$} \\
\hline AÑ̃ & hab/viv & 1/hab/dia & FuO & VARIABLE & TOTAL & FuO & VARIABLE & TOTAL & FuO & VARIABLE & TOTAL \\
\hline 2000 & 2,78 & 183 & 3,79 & 15,46 & 19,25 & 0,00 & 2,24 & 2,24 & 3,79 & 17,70 & 21,49 \\
\hline 20094 & 2,78 & 174 & 3,89 & 14,35 & 18,24 & 0,00 & $2,0 \theta$ & 2,09 & 3,89 & 16,45 & 20,34 \\
\hline 2005 & 2,72 & 162 & 4,03 & 13,17 & 17,20 & 0,00 & 1,84 & 1,84 & 4,03 & 15,01 & 19,04 \\
\hline 2006 & 2,72 & 150 & 4,16 & 11,9 & 16,05 & 0,00 & 1,77 & 1,77 & 4,16 & 13,66 & 17,82 \\
\hline 2007 & 2,72 & 151 & 4,36 & 12,36 & 16,72 & 0,00 & 1,81 & 1,81 & 4,36 & 14,17 & 18,53 \\
\hline 20008 & 2,72 & 139 & 4,52 & 11,51 & 16,03 & 0,00 & $1, \boldsymbol{\oplus}$ & 1,69 & 4,52 & 13,19 & 17,71 \\
\hline 2000 & $2, \pi 2$ & 132 & 4,90 & 11,32 & 16,22 & 0,00 & 1,65 & 1,65 & 4,90 & 12,97 & 17,87 \\
\hline 2010 & 2,72 & 126 & 4,99 & 10,66 & 15,65 & 0,00 & 1,57 & 1,57 & 4,99 & 12,24 & 17,23 \\
\hline \multicolumn{3}{|c|}{ Bilbao } & & & & & & & & & \\
\hline 20003 & 2,98 & 149 & 1,72 & 4,59 & 6,31 & 1,28 & 4,45 & 5,73 & 3,01 & 9,04 & 12,05 \\
\hline 2004 & $2, \boldsymbol{\theta}$ & 150 & 1,77 & 4,5 & 6,36 & 1,29 & 4,39 & 5,68 & 3,06 & 8,98 & 12,04 \\
\hline 2005 & 2,86 & 140 & 1,83 & 4,38 & 6,20 & 1,32 & 4,14 & 5,46 & 3,15 & 8,51 & 11,66 \\
\hline 2006 & 2,86 & 179 & 1,89 & 4,17 & 6,05 & 1,36 & 3,94 & 5,30 & 3,25 & 8,10 & 11,35 \\
\hline 2007 & 2,86 & 125 & 1,96 & 4,20 & 6,16 & 1,42 & 3,97 & 5,39 & 3,38 & 8,17 & 11,55 \\
\hline 20008 & 2,86 & 139 & 2,01 & $4, \pi$ & 6,78 & 1,45 & 4,51 & 5,96 & 3,46 & 9,28 & 12,73 \\
\hline 2009 & 2,86 & 126 & 2,11 & 4,55 & 6,67 & 1,53 & 4,30 & 5,83 & 3,64 & 8,86 & 12,50 \\
\hline 20010 & 2,86 & 124 & 2,19 & 4,51 & 6,71 & 1,56 & 4,26 & 5,82 & 3,75 & $8, \pi$ & 12,57 \\
\hline \multicolumn{3}{|c|}{ Ciudad Real } & & & & & & & & & \\
\hline 2003 & 3,03 & 184 & 1,68 & 7,65 & 9,32 & 0,00 & 4,15 & 4,15 & 1,68 & 11,80 & 13,47 \\
\hline 20004 & 2,93 & 179 & 1,73 & 6,48 & 8,21 & 0,00 & 3,81 & 3,81 & 1,73 & 10,29 & 12,02 \\
\hline 2005 & 2,88 & 174 & 1,78 & 5,79 & 7,57 & 0,00 & 3,65 & 3,65 & 1,78 & 9,44 & 11,22 \\
\hline 2006 & 2,88 & 166 & 1,84 & 5,59 & 7,44 & 0,00 & 3,54 & 3,54 & 1,84 & 9,14 & 10,98 \\
\hline 2007 & 2,88 & 163 & 1,92 & 5,66 & 7,58 & 0,00 & 3,60 & 3,60 & 1,92 & 9,26 & 11,18 \\
\hline 20008 & 2,88 & 155 & 1,97 & 5,41 & 7,38 & 0,00 & 3,48 & 3,48 & 1,97 & $8, \boldsymbol{8}$ & 10,87 \\
\hline 2009 & 2,88 & 146 & 2,07 & 5,16 & 7,23 & 0,00 & 3,36 & 3,36 & 2,07 & 8,52 & 10,59 \\
\hline 2010 & 2,88 & 141 & 2,07 & 4,90 & 6,97 & 0,00 & 3,21 & 3,21 & 2,07 & 8,11 & 10,18 \\
\hline \multicolumn{3}{|c|}{ Coruña, L } & & & & & & & & & \\
\hline 20003 & 3,06 & 143 & 2,81 & 3,73 & 6,54 & 0,35 & $3, \boldsymbol{\theta}$ & 4,04 & 3,16 & 7,41 & 10,57 \\
\hline 2004 & 3,1 & 155 & 3,01 & 4,31 & 7,32 & 0,36 & 4,05 & 4,41 & 3,37 & 8,36 & 11,73 \\
\hline 2005 & 3,09 & 152 & 3,13 & 4,28 & 7,41 & 0,37 & 3,88 & 4,25 & 3,50 & 8,16 & 11,66 \\
\hline 2006 & 3,09 & 159 & 3,28 & $3, \pi$ & 7,01 & 0,38 & 4,06 & 4,44 & 3,66 & 7,79 & 11,45 \\
\hline 2007 & 3,09 & 143 & 3,41 & 3,37 & 6,78 & 0,40 & $3, \pi$ & 4,10 & 3,81 & 7,07 & 10,88 \\
\hline 2008 & 3,09 & 146 & 4,42 & 3,55 & 7,97 & 0,41 & 4,10 & 4,51 & 4,83 & 7,66 & 12,49 \\
\hline 2009 & 3,09 & 139 & 4,56 & 3,28 & 7,84 & 0,42 & 3,96 & 4,38 & 4,98 & 7,24 & 12,22 \\
\hline 2010 & 3,09 & 140 & 4,62 & 3,33 & 7,95 & 0,42 & 4,00 & 4,42 & 5,04 & 7,33 & 12,37 \\
\hline \multicolumn{3}{|c|}{ Madrid } & & & & & & & & & \\
\hline 20003 & 2,97 & 166 & 2,90 & 6,73 & 9,63 & 1,03 & 4,20 & 5,22 & 3,93 & 10,92 & 14,85 \\
\hline 2009 & 2,96 & 171 & 2,81 & 6,77 & 9,58 & 1,00 & 4,19 & 5,19 & 3,81 & 10,96 & 14,77 \\
\hline 2005 & 2,96 & 159 & 3,37 & 5,85 & 9,22 & 1,13 & 4,29 & 5,42 & 4,50 & 10,14 & 14,64 \\
\hline 2006 & 2,96 & 148 & 4,25 & 4,87 & 9,12 & 1,28 & 4,51 & 5,79 & 5,53 & 9,38 & 14,91 \\
\hline 2007 & 2,96 & 150 & 4,37 & 5,00 & 9,37 & 1,35 & 4,81 & 6,17 & 5,72 & 9,82 & 15,54 \\
\hline 2008 & 2,96 & 144 & 4,55 & 5,00 & 9,55 & 1,41 & 4,81 & 6,22 & 5,96 & 9,81 & 15,77 \\
\hline 2009 & 2,96 & 145 & 4,67 & 5,16 & 9,83 & 1,44 & 4,96 & 6,40 & 6,11 & 10,12 & 16,23 \\
\hline 2010 & 2,96 & 142 & 4,67 & 5,06 & 9,73 & 1,44 & 4,87 & 6,31 & 6,11 & 9,93 & 16,04 \\
\hline \multicolumn{3}{|c|}{ Salamanca } & & & & & & & & & \\
\hline 20003 & 2,68 & 168 & 1,91 & 4,54 & 6,44 & 0,96 & 5,13 & 6,09 & 2,87 & 9,67 & 12,54 \\
\hline 20004 & 2,58 & 172 & 1,96 & 4,57 & 6,53 & 0,99 & 5,13 & 6,12 & 2,95 & $9, \pi$ & 12,66 \\
\hline 2005 & 2,65 & 160 & 2,09 & 4,54 & 6,63 & 0,92 & 4,79 & 5,71 & 3,01 & 9,33 & 12,34 \\
\hline 2006 & 2,65 & 147 & 2,16 & 4,10 & 6,25 & 0,95 & 4,47 & 5,42 & 3,11 & 8,57 & 11,68 \\
\hline 2007 & 2,65 & 154 & 2,24 & 4,58 & 6,82 & 0,99 & 4,90 & 5,89 & 3,23 & 9,48 & $12, \pi$ \\
\hline 20003 & 2,65 & 153 & 2,32 & $4, \boldsymbol{\theta}$ & 7,00 & 1,02 & 5,32 & 6,34 & 3,34 & 10,00 & 13,34 \\
\hline 2009 & 2,65 & 162 & 2,43 & 5,37 & 7,80 & 1,07 & 5,97 & 7,04 & 3,50 & 11,34 & 14,84 \\
\hline 20010 & 2,65 & 163 & 2,43 & 5,30 & 7,73 & 1,07 & 6,02 & 7,09 & 3,50 & 11,32 & 14,82 \\
\hline \multicolumn{3}{|c|}{ Sevilla } & & & & & & & & & \\
\hline 20003 & 3,19 & 184 & 2,17 & 9,31 & 11,48 & 0,79 & 7,94 & 8,73 & 2,96 & 17,25 & $\mathbf{2 0 , 2 1}$ \\
\hline 20004 & 3,17 & 189 & 2,24 & 10,23 & 12,46 & 0,81 & 8,53 & 9,34 & 3,05 & 18,75 & 21,80 \\
\hline 2005 & 3,14 & 195 & 2,31 & 11,12 & 13,43 & 0,84 & 9,07 & 9,91 & 3,15 & 20,19 & 23,34 \\
\hline 2006 & 3,14 & 176 & 2,39 & 9,19 & 11,57 & 0,86 & 8,99 & 9,85 & 3,25 & 18,18 & 21,43 \\
\hline 20008 & 3,14 & 157 & 2,53 & 8,85 & 11,38 & 0,99 & 8,94 & 9,92 & 3,52 & 17,78 & 21,30 \\
\hline 2000 & 3,14 & 156 & 2,66 & 9,30 & 11,96 & 1,06 & 9,68 & 10,74 & 3,72 & 18,98 & $2 \mathbf{2}, \mathbf{\pi}$ \\
\hline 2010 & 3,14 & 153 & 3,62 & 9,07 & 12,68 & 2,11 & 9,35 & 11,46 & 5,73 & 18,42 & 24,15 \\
\hline
\end{tabular}

Fuente: elaboración propia 
este autor, la conclusión es clara, "la concentración de la edificación rentabiliza de manera más eficiente las infraestructuras hidráulicas de distribución de agua potable y saneamiento" (Ibid. p.21).

La correlación del número de viviendas respecto al consumo de agua ha sido significativa en el $86 \%$ de las ciudades estudiadas, cumpliéndose en todas ellas a excepción de A Coruña. En el caso de las viviendas la correlación es negativa, disminuye el consumo a pesar del aumento del $\mathrm{n}^{\mathrm{o}}$ de viviendas. La explicación puede radicar en que las nuevas viviendas no tienen por qué ser viviendas ocupadas.

Figura 5. Consumo diario según superficie de la vivienda y otras variables explicativas

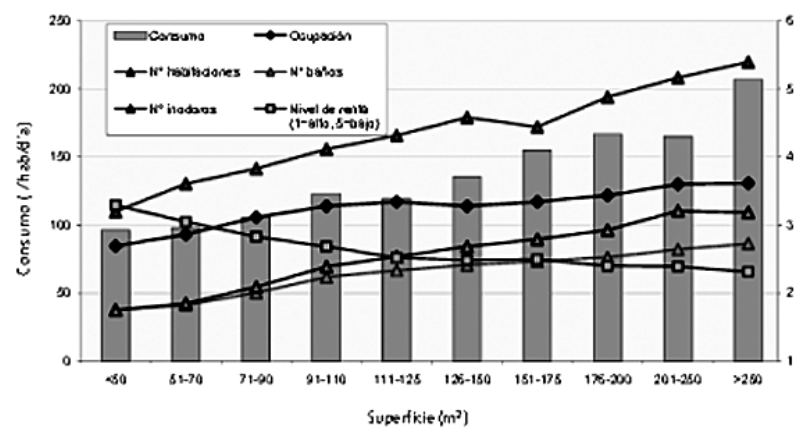

Nota. El nivel de renta se representa gráficamente a la inversa del resto de valores, lo que puede dar lugar a errores de interpretación. Fuente: Cubillo, 2008:100-102

En lo que respecta a la renta disponible, seleccionamos la renta bruta familiar disponible, observando la existencia de correlación en todas las ciudades menos Bilbao y A Coruña.

Respecto de la renta, el poder adquisitivo de las familias tiene efectos sobre los usos de agua asociados a mayores niveles de bienestar. A partir de un determinado nivel de renta, hay un doble impacto sobre el consumo de agua; por un lado, genera un impacto positivo al permitir la adquisición de tecnología ligada a la eficiencia en el uso doméstico del agua (grifería con aireadores, cisternas de doble descarga, entre otras), pero, por otro lado, tiene efectos negativos sobre el consumo ligado, principalmente, a usos no esenciales, caso de acceso a viviendas unifamiliares ajardinadas (Dalhuisen et al., 2003).

En el estudio realizado por Cubillo para la Comunidad de Madrid (2008) se muestra una correlación entre consumo-tamaño de la vivienda y renta familiar. Se incrementa el tamaño de la vivienda, el número de baños y, posiblemente lo más importante, los citados usos no esenciales: zonas ajardinadas y piscinas, principalmente. Según Flörke y Alcamo, 2004, la relación consumo-renta per capita evoluciona bajo un modelo sigmoidal (Figura 6). De esta forma, durante un tiempo con el incremento del nivel de renta hay un descenso del consumo, debido a la aplicación de sencillas tecnologías que permiten el ahorro, pero luego vuelve a producirse un incremento en los consumos al buscarse otros modelos de bienestar (principalmente vivienda con más baños, jardín, piscina...), que vuelven a incrementar el consumo. 
Utilizando los datos de evolución de las captaciones y usos domésticos y la renta española de forma global, a partir del año 2005 se observa un cambio de tendencia, similar al observado en otros países de nuestro entorno a principios de la década, con reducciones en el volumen total de captaciones y usos, aunque éstos no pueden ser sólo atribuibles al factor renta. El estudio de Cubillo muestra como al aumentar la renta disponible se introducen más electrodomésticos en los hogares y se aumenta el consumo, supuestamente en contra a lo que se concluye en otros trabajos realizados en los que el uso de estos electrodomésticos de línea blanca y otras sencillas tecno-

Figura 6. Modelo conceptual de la evolución del uso doméstico del agua, y escenarios posibles según las medidas que se adopten en el marco de una política de agua.

Fuente: Elaboración propia

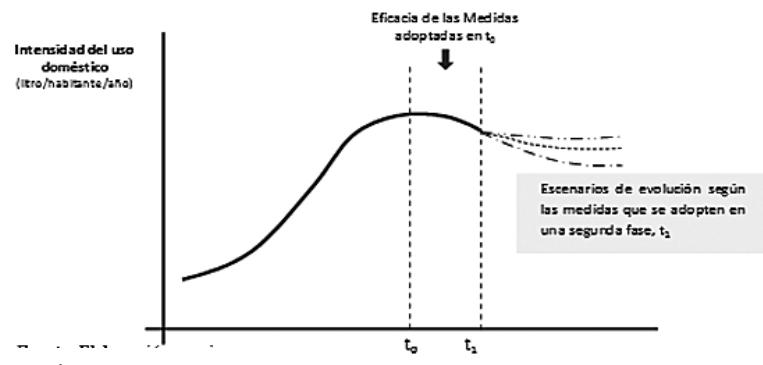

logías cada vez más extendidas que permiten optimizar la eficiencia, caso de cisternas de doble descarga, grifería con reductores de caudal o perlizadores, etc. (Flörke y Alcamo, 2004; WSAA, 2010).

Entendemos que los resultados de Cubillo, en contra de lo opinado por el autor, bien pueden encontrarse en línea con trabajos realizados en Estados Unidos y Australia, si se hiciera un análisis de lo sucedido en un plazo más amplio que el del estudio realizado por Cubillo (mide y compara los años: 2002 y 2003, confrontando los resultados con los del año 2008). En caso de hacerse un seguimiento de sus resultados, tal vez podría llegar a corroborarse que sus resultados se encuentran en línea con los citados trabajos de Estados Unidos y Australia, según los cuales al incrementarse la renta los consumos se optimizan hasta un punto en el que vuelven a incrementarse los consumos, como consecuencia de cambios en las costumbres y estilos de vida. No obstante, los resultados obtenidos en Australia mediante la aplicación de medidas de optimización del uso del agua utilizando una combinación de fomento del uso de tecnologías y precios, sobre todo en el uso de agua doméstica "de puertas hacia fuera", son indiscutibles (WSAA, 2010).

En las siete ciudades objeto de nuestro estudio, encontramos correlación significativa de la renta con respecto al consumo en el $71 \%$ de las ciudades, es decir, en todas menos en Bilbao y A Coruña. Es una correlación es negativa, disminuye el consumo cuando aumenta la renta. Vemos como se cumple lo mismo que se ha visto en los resultados obtenidos en los trabajos mencionados anteriormente, en lo que al periodo inicial de optimización de consumos se refiere.

Aunque la variable temperatura no se ha incluido en el análisis de correlación con la herramienta de análisis SPSS, si hemos realizado un estudio grafico de la evo- 
lución del consumo en relación a las temperaturas medias anuales, comprobando que efectivamente están correlacionadas. Consideramos que igual de importante es la temperatura en el análisis de consumo como las precipitaciones, por lo que debería incorporarse también como variable.

La temperatura y las precipitaciones tienen influencia en el consumo de agua doméstica. Aunque existe una correlación: a mayor temperatura, mayor consumo. Esta afirmación tiene importantes matices. En el estudio de Cubillo, se ha observado que el consumo aumenta para temperaturas superiores a los $25-30 \mathrm{oC}$, tanto el doméstico global como el de exterior, y para temperaturas máximas próximas a los $40 \mathrm{oC}$ el consumo diario es prácticamente un 50\% superior a días en los que la temperatura se encuentra por debajo de los 5oC (Cubillo, 2008:109). Estos incrementos también varían según el tipo de vivienda. Así, en viviendas plurifamiliares se observa un incremento en consumo por aumento de temperatura, para luego aparecer un descenso que el autor atribuye a motivos vacacionales; en tanto que en viviendas unifamiliares el aumento es "prácticamente exponencial con la temperatura" sin que se observen descensos. En el caso de las precipitaciones, como puede concluirse de forma intuitiva, el efecto es el contrario, es decir, a mayores precipitaciones, menor consumo, siendo la correlación más fuerte que la mostrada por la temperatura. Ahora bien, este es un efecto que se observa tan sólo en viviendas unifamiliares (en viviendas sin consumo exterior el consumo es prácticamente independiente de esta variable climatológica); y que para apreciarse la precipitación debe ser superior a un intervalo comprendido entre los 15 y los 20 milímetros de precipitación (Ibid. p.112).

Así pues, si hay una correlación entre temperatura y consumo, que es mucho más fuerte en viviendas con consumos exteriores, pero es una variable a considerar sólo a partir de $\operatorname{los} 30^{\circ} \mathrm{C}$. En tanto que la correlación entre las precipitaciones y los consumos sólo se da en el caso de viviendas con usos domiciliarios exteriores.

En nuestro estudio hemos recopilado las temperaturas medias máximas de los cuatro meses de verano (de junio a septiembre) y las hemos comparado con el consumo medio anual. Se puede comprobar en el gráfico integrado por las siete ciudades que el comportamiento del consumo y la temperatura es sincronizado salvo en los últimos años donde la temperatura ha sufrido un repunte y el consumo se ha mantenido mas o menos estable a la baja (figura 7).

Cerrar este apartado de presentación y discusión de los resultados obtenidos, señalando que la disminución de los recursos disponibles, ya sea en cantidad y/o calidad, hace necesario seguir incidiendo en la optimización, disminución, del consumo de agua en sus distintos usos. Posiblemente el uso doméstico es el que actualmente cuenta con una tendencia de consumo a la baja más favorable, pero es necesario seguir trabajando en este tema sin olvidar que cuando los consumidores ahorran agua, los ingresos de las administraciones gestoras del recurso obtenidos vía tarifa también lo hacen y son precisamente los consumos domésticos los que cuentan con un precio mayor. Así pues, se hace necesario buscar un equilibrio dinámico entre la sostenibilidad ambiental del recurso y la sostenibilidad financiera de aquellos que tienen encomendada tanto su gestión, como la prestación de los servicios vinculados al agua. 
Figura 7. Comparativo de consumos y temperaturas medias de las siete ciudades (en millones de $\mathrm{m}^{3} /$ año y ${ }^{\circ} \mathrm{C}$ )

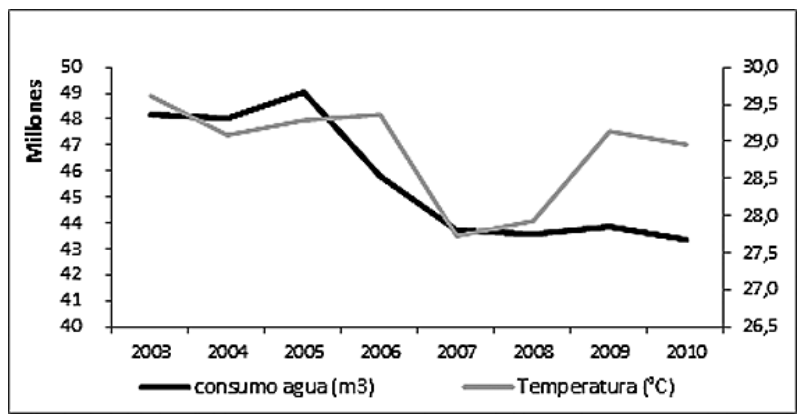

Fuente: elaboración propia

Como se observa en la Figura 8, se evidencia que, aunque en todas las ciudades ha habido una clara subida en las tarifas del agua durante el periodo analizado en este estudio, esto no ha servido para el objetivo de controlar el consumo. Ciudades como Barcelona y A Coruña, con unos incrementos similares han obtenido reducciones de consumo muy dispares, siendo más eficaces en la primera, demostrando que los actuales incrementos de las tarifas (que siguen teniendo un escaso peso en la renta familiar), no siempre consiguen el mismo impacto en la reducción del consumo. Ciudades como Ciudad Real y Sevilla con reducciones similares en el consumo entre un $13 \%$ y un $18 \%$, respectivamente, ha sido objeto de incrementos tarifarios absolutamente distintos ( $+4 \%$ en Ciudad Real frente al 46\% de Sevilla).

Figura 8. Comparativa por ciudades de las variaciones precio-consumo de agua (2003-2010)

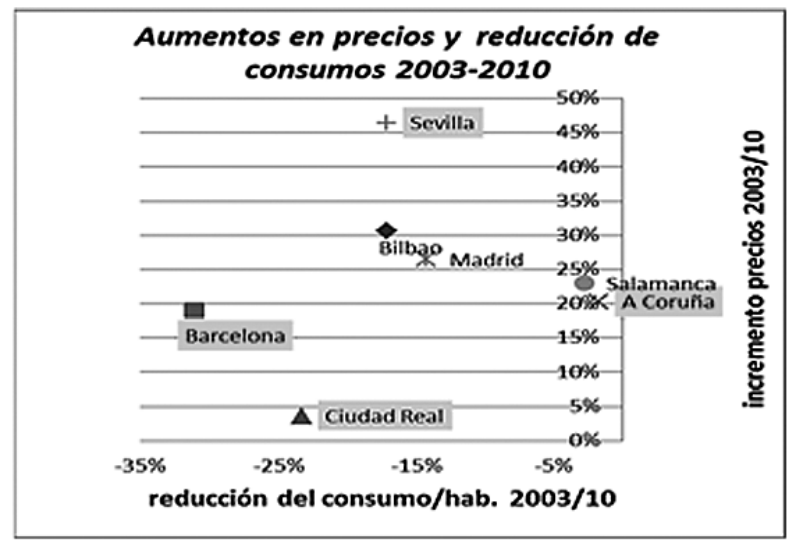

Fuente: elaboración propia

Elaborando un ranking de las variaciones por ciudades respecto de las variaciones precio-consumo y la parte de la tarifa que es fija, se aprecian mejor las disparidades, principalmente en el apartado de la cuota fija, que podríamos considerar 
rompe el necesario principio de equidad (en realidad de solidaridad interterritorial), si por equidad entendemos la obligación de cubrir las necesidades básicas del abastecimiento sin que se produzcan discriminaciones en el territorio nacional.

La figura 9 muestra la existencia de una clara diferenciación en la cuota fija pagada en las distintas ciudades. Así, a modo de ejemplo, en Madrid se paga el triple que en Ciudad Real, independientemente del consumo. El contenido del apartado relativo a la cuota fija, se concluye debe ser restructurado a fin de cumplir el principio de equidad contenido en la DMA.

Un problema detectado en el método actual calculo de la estructura tarifaria, es que su computo se basa en un consumo y en unos costes estimados que podrían provocar distorsiones en los precios adecuados, en el caso de que finalmente estos fueran mayores o menores que lo previsto. Esto puede provocar, por ejemplo, que en condiciones climatológicas adversas no debidamente planificadas, no puedan ser repercutidos en las tarifas los costes reales o unos consumos mayores. Ello incidiría en la no transmisión de señales a los consumidores sobre el verdadero coste del servicio que se ofrece y la escasez del recurso.

Hemos comprobado que en las décadas siguientes a los años 80 y 90 , del siglo pasado, apenas se ha avanzado en los sistemas tarifarios. Con las tarifas se consiguió inicialmente un efecto de adecuación del consumo que no ha mantenido esa tendencia positiva. $\mathrm{O}$ lo que es igual, la tarifa como herramienta de control y reducción del consumo ha perdido eficacia, llegando a un punto, el actual, en el que bien puede afirmarse que ya no es efectiva como instrumento para incentivar el ahorro en el consumo, que continúen esa mejora y disminuyan aún más el consumo. Además hay que añadir el efecto adverso de la situación de stress hídrico en algunas cuencas españolas

Figura 9. Ranking de pago mensual por vivienda y diferenciación cuota fija-variable de la tarifa 2010

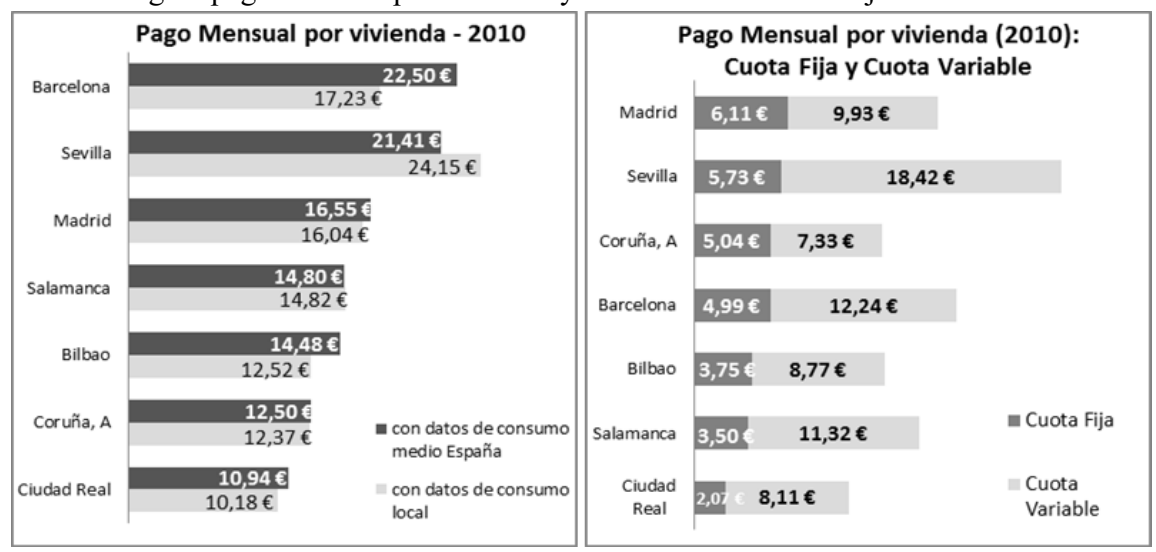

Fuente: Elaboración propia

Hay una fuerte politización de gestión hidráulica, con una conflictiva disgregación de competencias, que afecta a la gestión eficiente del recurso a escala nacional. Esta politización es fuente de graves conflictos territoriales, como se pone de manifiesto en la lucha 
por las competencias entre CC.AA. Esto supone un riesgo de "regionalización" del recurso que, con independencia de cuestiones legales o sociales, supone una pérdida de eficiencia económica. Se hace necesario mejorar la gobernanza, desde la esfera estatal, y seguir abundando en una mayor coordinación estado-autonomías-ayuntamientos para la gestión.

\section{CONCLUSIONES}

Nuestra hipótesis de partida era demostrar si el actual sistema tarifario español se adecua, o no, a la situación del recurso en España y a los objetivos previstos en la Directiva Marco del Agua. Tras el trabajo de investigación realizado, la conclusión principal es que no, el actual sistema tarifario español no se adecúa a la realidad hídrica española y no es una herramienta eficaz para el control de la demanda de agua para uso doméstico. A mayor abundamiento, tampoco cumple con los requisitos recogidos en la Directiva Marco del Agua, por lo que no contribuye a cumplir el objetivo básico de la Directiva: promover "un uso sostenible del agua".

Sobre la base de nuestra conclusión, entendemos que el actual sistema tarifario español debería ser reformado. Es necesario abordar una reforma de la política de aguas, europea y española, para colaborar en la estabilización hídrica de ciertas regiones al tiempo que se busca una economía de bajo consumo de agua (Frerot, 2009), como ya se hace desde hace años respecto del compromiso europeo de una economía baja en carbono para limitar los efectos del cambio climático.

La Figura 10 recoge el gráfico de evolución del consumo doméstico del agua en España en base a los posibles escenarios de futuro, a corto y medio plazo, que se materialicen en base a las medidas que se planifiquen y adopten a lo largo de la actual Legislatura (2011-2015).

Figura 10.- Evolución del uso doméstico del agua en España, y escenarios posibles según las medidas que se adopten en la legislatura 2011-2015

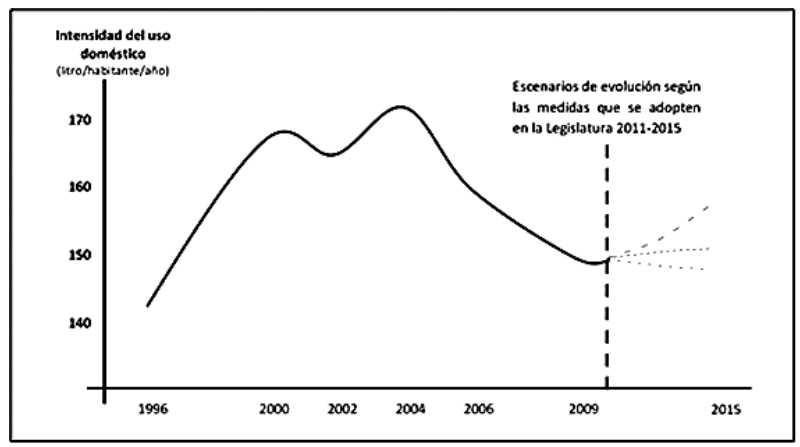

Fuente: elaboración propia

La falta de transparencia informativa del sector, enmascara el hecho de que los bajos niveles tarifarios que están siendo aplicados en buena parte de España no permiten cumplir los principios de recuperación de costes, ni los objetivos de conservación y eficiencia del recurso, tal y como se pide en la DMA. 
Las previsiones para la UE, y más particularmente para España, como consecuencia de la evolución actual y de las previsiones a medio plazo, consecuencia del cambio climático, anuncian un incremento estacional del estrés hídrico (en los meses de verano), lo que ha de tenerse en consideración en la gestión del recurso. Máxime cuando algunas de nuestras cuencas hidrográficas, caso de la cuenca del Guadalquivir, cuentan en la actualidad con un estrés hídrico severo.

Las actuaciones políticas en la UE van encaminadas a gestionar el agua de forma que se consiga una reducción de la demanda, no al aumento de la oferta. El modelo europeo de gestión es un modelo que busca la "sostenibilidad", no un mero modelo mixto que conjugue los anteriores. Este hecho no debería seguir siendo ignorado por el regulador español, de cara a acometer una revisión, más que necesaria, imprescindible, del actual Plan Hidrológico Nacional.

A lo largo del estudio hemos comprobado la existencia de importantes diferencias de consumo per cápita que existen entre Comunidades Autónomas. Así, según el comportamiento respecto del consumo, podemos agrupar las Comunidades en tres bloques, las que se encuentran sistemáticamente en valores superiores a la media, las que se encuentran en el entorno de la media, y las que registran los mejores comportamientos. Según los datos del Ministerio de Medio Ambiente para el periodo 19962003, se apreciaba un comportamiento "sistemático malo" de algunas Comunidades, en el sentido de que no se observan esfuerzos de reducción del consumo de agua o que tales esfuerzos no han sido efectivos. Es el caso de Castilla La Mancha, Andalucía, Cataluña y Castilla León, de las que seleccionamos importantes ciudades para ver su posterior evolución en precios y consumos. Así, en el siguiente periodo de análisis, periodo 2003-2009, se observan cambios favorables de control del consumo en todas ellas; pasando a ser las Comunidades con valores más altos de consumo, por encima de la media, Cantabria, Asturias o Extremadura. Ahora bien, nos parece más interesante llamar la atención sobre dos tendencias muy marcadas en ese periodo de tiempo: en el lado positivo, los consumos decrecientes de Cataluña; en el lado negativo del comportamiento el marcado empeoramiento de la C. Valenciana, así como la tendencia de Murcia.

Desde el punto de vista tendencial, a lo largo del periodo de análisis 2003-2010, los crecimientos de precios son cada vez mayores y las reducciones del consumo de agua domestico son cada vez menores. En definitiva, los incrementos de precios tienen menor incidencia sobre el consumo a medida que avanzamos en el tiempo. Esto nos lleva a concluir lo necesario que es acometer de forma inmediata a la "reinvención" del actual sistema tarifario. Además, situaciones provocadas por las sequías, como la ocurrida en Barcelona en 2008, ponen claramente de manifiesto que los costes reales de la "no planificación", son mucho más altos (económica, social y políticamente) que una planificación estratégica del recurso a medio y largo plazo.

\section{7.-BIBLIOGRAFÍA}

ASOCIACION ESPAÑOLA DE ABASTECIMIENTO DE AGUAS Y SANEAMIENTO (2004): VIII Encuesta Nacional de Suministro de Agua Potable y Saneamiento en España 2002. Madrid. 
- (2008): XI Encuesta nacional. Suministro de agua potable y saneamiento en España. Edita AEAS, Madrid.

- (2009): Tarifas 2009. Precio de los servicios de abastecimiento y saneamiento en España. Edita AEAS, Madrid.

- (2011) "El agua para uso doméstico cuesta en España seis veces menos que en Dinamarca", información de la AEAS publicada en varios diarios de difusión nacional, entre ellos el diario económico Cinco Días, el 6 de junio de 2011. Noticia disponible en http:/www.cincodias.com/articulo/economic.

AGENCIA EUROPEA DE MEDIO AMBIENTE, (2010): El Medio Ambiente en Europa. Estado y perspectivas 2010. Síntesis. Agencia Europea de Medio Ambiente. Copenhague.

BJÖRKLUND, G.; CONNOR, R.; GOUJON, A.; HELLMUTH, P.; RAST, W. y WINEPENNY, J. (2009) "Demographic, economic and social drivers", en Water in a Changing World. UNWWD Report 3. UNESCO Publishing \& Earthscan, Londres. pp.29-40.

BULLOCK, A.; COSGROVE, W.; VAN DER HOCH, W. y WINPENNY, J. (2009): "Getting out of the box-linking water to decisions for sustainable development", en UNWATER (2009) Water in a Changing World. UNWWD Report 3. UNESCO Publishing \& Earthscan, Londres. pp.3-23.

CUBILLO, F.; MORENO, T. Y ORTEGA, S. (2008): "Microcomponentes y factores explicativos del consumo doméstico de agua en la Comunidad de Madrid". Colección Cuadernos de I+D+i. Canal de Isabel II, Madrid.

ENVIRONMENTAL EUROPEAN AGENCY (2006): EEA (2006): "Urban Sprawl in Europe. The ignored Challenge". EEA Report 10/2006. Luxemburgo.

(2009): "Water Resources across Europe. Confronting water scarcity and drought". EEA Report 2/2009. Luxemburgo.

FLÖRKE, M. Y ALCAMO, J. (2004): “European Outlook on Water Use”. Final Report. Disponible en: http://scenarios.ew.eea.europa.eu

FREROT, A. (2009): "La Unión Europea ante el reto de la escasez del agua". Cuestiones sobre Europa, $\mathrm{n}^{\mathrm{o}}$ 126, de 2 de febrero de 2009. Fundación Robert Schuman, pp. 1-11.

INE (2001): “Estadística del Agua 1999”. Gabinete de prensa, 8 de marzo del 2001. Instituto Nacional de Estadística.

- (2003): "Encuesta sobre el suministro y tratamiento del agua 2001". Gabinete de prensa, 1 de julio del 2003. Instituto Nacional de Estadística.

- (2011): Informacion on line disponible en: http://www.ine.es/ jaxi/ menu.do?type $=$ pcaxis $\&$ path $=\% 2 \mathrm{Ft} 26 \% 2 \mathrm{Fp} 067 \% 2 \mathrm{Fp} 01 \&$ file $=$ inebase $\& \mathrm{~L}=$

FLÖRKE, M. y ALCAMO, J. (2004): European Outlook on Water Use. Final Report. Disponible en: http://scenarios.ew.eea.europa.eu

HÖGLUND, L. (1999): "Household demand for water in Sweden with implications of potential tax on water use". Water Resources Research Vol. 35(12): 3853-3863.

LUND, J. Y CAHILL, R. (2011): "Can California further reduce urban water use?" disponible en ttp:/californiawaterblog.com/2011/06/08/can-california-furtherreduce-urban-water-use/ [24.10.2011]. 
MARCH, H. y SAURI, D. (2009): "What lies behind domestic water use? A review essay on the drivers of domestic water consumption", Boletín de la AGE, $\mathrm{n}^{\mathrm{0}} 50$ 2009: 297-314.

MAYER, P.N.; DE OREO, W.B.; OPITZ, E; KEIFER, J.C.; DAVIS, W.Y.; ZIEGLELEWSKI, B. y NELSON, J. (1999): "Residential End Uses of Water Study (REUWS)". American Water Works Association Research Foundation. Disponible en http://www.awwa.org/publications

MINISTERIO DE MEDIO AMBIENTE (2007a): Informe sobre la situación actual y evolución de los ingresos y tarifas de los servicios urbanos del agua. Grupo de Análisis Económico MMA.

- (2007b): "Precios y costes de los servicios del agua en España. Informe integrado de recuperación de costes de los servicios del agua en España, artículo 5 y anejo III de la Directiva Marco del Agua en España”. Madrid.

- (2007c): "El agua en la economía española: situación y perspectivas. Informe integrado del análisis económico de los usos del agua. Artículo 5 y anejo II y III de la Directiva Marco del Agua en España". Madrid, enero de 2007.

MUÑOZ, F. (2003): "Lock living: urban sprawl in Mediterranean cities". Cities. Vol. 20 (6): 381-385.

OECD (1993): OECD Core set of Indicators for Environmental Performance Reviews. OECD Environment Monographs No. 83. OECD. Paris.

PARÉS, A.; DOMENE, E.; Y SAURÍ, D. (2003): "Modelos urbanos y consumo de agua. El riego de los jardines privados en la región metropolitana de Barcelona". Investigaciones Geográficas, 32. Instituto Universitario de Geografía. Universidad de Alicante.

RICO AMORÓS, A. (2007): "Tipologías de consumo de agua en abastecimientos urbano-turísticos dela Comunidad Valenciana”, Investigaciones Geográficas, $\mathrm{n}^{\circ}$ 42, Instituto Universitario de Geografía, Universidad de Alicante, pp. 5-34.

SÁNCHEZ GARCÍA, V.E. (2012): "Eficiencia del sistema de tarifas de agua para el control de la demanda de uso doméstico. Estudio de casos". Tesis Doctoral. Departamento de Economía Aplicada I, Universidad Rey Juan Carlos de Madrid.

SMITH, A. y ALI, M. (2006): "Understanding the impact of cultural and religious water use". Water and Environment Journal, Vol. 20(4):203-209.

STOCKHOLM INTERNATIONAL WATER INSTITUTE (2005): "Making Water a Part of Economic Development. The Economic Benefits of Improved Water Services". SIWI. Disponible en www.who.int/water_sanitation_health/waterand macroecon.pdf

SOTELO NAVALPOTRO, J.A.; SOTELO PÉREZ, M.; Y GARCÍA QUIROGA, F. (2011): "Análisis de "coste-beneficio" y "coste-eficiencia" de la Huella Hídrica en España", Observatorio medioambiental, 2011(4): 225-254. http://dx.doi.org/10.5209/rev_OBMD.2011.v14.37309

WATER SERVICES ASSOCIAT̄ION OF AUSTRALIA (2010): "Implications of population growth on Australia on urban water", Water Services Association of Australia - Occasional Paper ${ }^{\circ} 25$. Sidney. 